\title{
Later Life: Living Alone, Social Connectedness and ICT
}

\author{
Alma L. Culén \\ University of Oslo, Department of Informatics, Oslo, Norway \\ almira@ifi.uio.no
}

\begin{abstract}
The paper presents a qualitative, interview-based study that seeks to describe participants' perceptions and experiences with information and communication technology. The participants in the study were active people, aged 67 and over, who live alone in an urban setting. Interactionist theory of loneliness was used to guide the inquiry, in particular regarding the perception of the relation between the quality and quantity of connections, loneliness, and technology. A set of visual tools such as communication maps and cards were made to aid reflections and associations during interviews.
\end{abstract}

Keywords: Loneliness, social connectedness, communication technology, elderly.

\section{Introduction}

In 1960, life expectancy at birth in Norway was 71 years for men and 76 for women. The projection for 2030 was 79 for men and 85 for women, as reported in the Active Aging report for 2003 [1]. In 2013, these numbers were already somewhat higher than predicted for 2030: 79,6 for men and 86,5 for women [2]. In 2014, $11 \%$ of the population was over the age of 67 , but that number is growing fast and is predicted to double by 2025 [2]. Many of those over 67 are, and will be, living alone [3], increasingly so in urban areas [4].

The living arrangements of elderly have clear implications for policy makers. They affect the need for care and resources. Those elderly who live alone tend to require more of both. In the National Council for Senior Citizens' action plan [5], it is stated that three out of ten people who live alone suffer from depression. Loneliness and depression are among the main reasons for elderly living alone to move into care homes [6]. Furthermore, a positive correlation between loneliness and functional decline and death is reported [7].

An extensive cross-cultural study of loneliness in Europe was conducted recently [8]. The study included 14 countries and tested several types of explanations for observed differences in loneliness: differences in demographic characteristics, wealth and health, and social networks. It showed that frequent contacts with adult children, social participation, and providing support to family members were important in preventing and alleviating loneliness in almost all countries. The study suggested further that increasing social connectedness is an important factor for reducing loneliness. A systematic overview of the literature on an effectiveness of interventions aiming to increase social connectedness was presented in [9]. It showed that there was no evi- 
dence for many of interventions that they worked, or, were transferable to different settings. The findings further suggested that the most effective interventions were based on educational or support oriented group activities. The most ineffective types of interventions were based on one-to-one social support, advice giving, health assessment or information sharing.

Recognizing effects of loneliness on the aging population and the need for solutions to the social isolation problem also engages the human-computer interaction (HCI) community. Design, often co-design with elderly, of new interfaces, interaction modes and new technologies, is seen within the HCI community as a powerful possibility for the field to contribute to solving growing challenges related to aging populations [10]. However, studies show that the use of information and communication technology (ICT) among elderly is still controversial, see, for example, [11-14]. Despite inconclusive results, many studies end on a technology deterministic note that future, easier to use technologies are going to solve problems they considered.

A look at statistics on the ICT use among elderly in Norway, provides the following data: in 2014, according to the Norwegian Statistical Bureau [15], the use of PCs for the age group $65-74$ was $76 \%$. In contrast, $95 \%$ of those under the age of 65 used computers. The Internet use was reported to be similar. However, the use of mobile and smartphones to connect to the Internet outside of a home was only $20 \%$ among those over 65 . The corresponding percentage for those under 65 was $92 \%$. These numbers imply that age-related digital divide still exists. How does this divide affect elderly living alone? Can technology help to solve or diminish challenges related to social connectedness for those living alone?

This paper presents a qualitative study based on in-depth interviews with six elderly over 65 who are living alone. The interviews were conducted using tools developed to facilitate and visualize reflections around the use of ICT and connectedness to others.

The primary aim of the study was to explore how well-educated, active elderly living alone view the potential of present and future technologies to support social connectedness and possibly reduce the sense of loneliness. The secondary aim was to explore whether tools that were made to assist reflections during interviews were effective in soliciting rich responses from interviewees.

The results of the study show that while the participants were not technology shy, they did not have technology deterministic views either. Personal contacts still mattered the most. In some cases, the choice to not use the technology was motivated by an ideological stance that it still should be possible to do things through human interaction, i.e. walk to the bank or the library and talk to a human rather than the Internet. Further, it was found that tools supported introspective and reflective processes to a varying degree, but that the social mapping has worked well.

The paper is structured as follows: the next section provides a brief description of the interactionist theory that guided the inquiry. In Section 3, the method, the choice of participants, the interview guide and the tools designed to aid interviews are presented. The analysis and the discussion are presented in Section 4 , followed by a conclusion. 


\section{$2 \quad$ Interactionist Theory of Loneliness}

The term loneliness indicates a subjective perception of an individual that the number of relationships is smaller than the individual considers desirable, or that the level of intimacy that the individual wishes for, has not been realized. Living alone does not automatically imply the loneliness. It is possible to live alone and not feel lonely, due to the presence of meaningful relations with, for example, adult children [16]. The reverse, being surrounded by others and still feeling lonely [17], is also possible. Thus, the link between living alone and loneliness is not a strong one. Many studies explore how the elderly experience their social situation, e.g., [18]. Various psychological theories have been formulated, among them existential, cognitive, psychodynamic and interactionist. The latter guided the research presented in this paper. Interactionist theory, see Weiss [19], suggests that there are two main components to loneliness: emotional loneliness and social loneliness. The first one arises in the absence of attachments, such as the absence of a meaningful relation with an adult child. The social loneliness is viewed as a lack of an appropriate network. Thus, individuals may evaluate their emotional and social loneliness subjectively, not only in terms of the quality, but also the quantity of social connections. If so, what and how could ICT support? A hypothesis could be made that the technology-supported communication is inferior to in-person connection and an impeding factor for the quality of connections. At the same time, it could be hypothesized that it could be a positive influence on increasing a number of connections. How elderly, living alone actually think about the role of technology in relation to social connectedness is of interest.

\section{Method}

The study takes a qualitative approach, seeking to describe the participants' perceptions and experiences of living alone, and their communication patterns with others that may or may not include the technology. Qualitative research is well suited to inquiry about human behavior, motives, views and challenges [20]. It can complement well quantitative studies on aging, loneliness and quality of life that abound in the literature in nursing, gerontology, psychology and even human-computer interaction (HCI) design.

When it comes to studies on the use of technology, HCI researchers frequently use ethnographic approaches. However, as described in [21], ethnography in HCI is often misused and in order to be perceived as having relevance for the field, such research is often forced to conclude with some 'implications for design'. Furthermore, in this study, the observations would need to take place in participants' homes. This could give rise to a number of other problems, among them ethical. Thus, in-depth interviews were chosen as the main approach. In addition, a set of tools consisting of communication maps, cards, and vignettes, inspired by participatory and co-design techniques $[22,23]$, was developed as an aid for reflection during the interview.

The following sections describe the tools, the choice of participants and finally, provide an interview plan. 


\subsection{Tools made to support the interviews}

\section{Communication maps.}

Inspired by the social mapping and, in particular, a technique described in [24], communication maps were developed, see Fig. 1 and [25]. The communication maps consist of three maps (friends and family, contacts and services and future technology), colored pens and images representing different communication platforms (e.g., phones, tablets, laptops, desktops), communication channels (e.g., Skype, email, call, SMS, chat, social media) and images of some future technologies (e.g., holographic phones, sensors, implant chips). The participants could, in addition, draw anything else they thought was relevant directly to the map. The maps, see Fig. 1, had an individual (represented by the word ' $m e$ ') positioned at the bottom of the map. Two circles were drawn to separate connections that are very close, close and not close. The participants were instructed to show their connections accordingly. Whether closeness was understood as intimacy or a physical proximity was left to each of the participants to decide. Alternatively, they could also arrange contacts by the frequency of communication. The other maps were used in a similar way.

The process of making and reflecting over these maps, in particular the first one, served as an opening for the conversation.
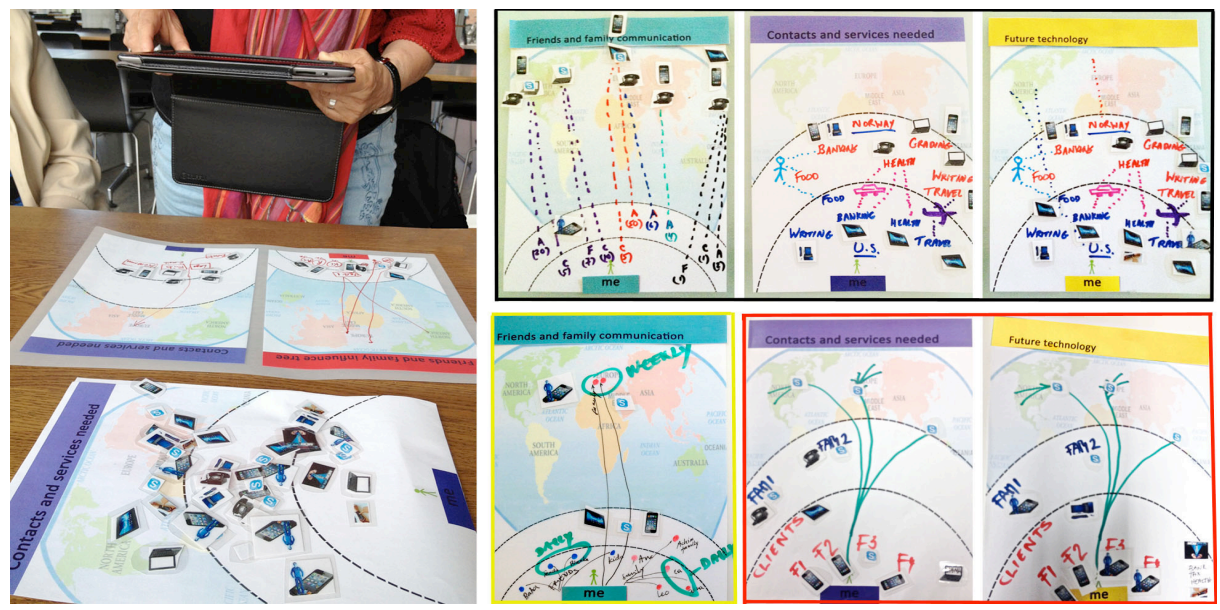

Fig. 1. A participant used the iPad to repeatedly take pictures of her maps. She did not consider looking at her relations in this way before. The image on the right shows examples of maps made by other participants.

\section{Communication cards.}

Instead of using the maps, one interview utilized a set of cards, with the same idea of being able to represent close and distant relations (both geographically and in terms of intimacy) and the technology supporting those connections. The reason for making and testing cards in addition to the maps was that they worked well in other situations, e.g., [26] for broad explorations. Furthermore, images on cards were large and could make viewing easier for participants, see Fig. 2. 
The cards were tested using a quick and dirty technique with three university students in order to ensure that images conveyed the meaning clearly and quickly. The concepts used in this process are those of immediacy and impedance, see [27]. This was done by allowing viewing of the image for a second or two, asking a tester for their immediate understanding of the image, recording the answer and then presenting the same image, with a word or two of the explanatory text. If the image was not understood correctly, inquiry into what impeded the correct understanding was made. Then a decision was made whether to include the image into the card set.
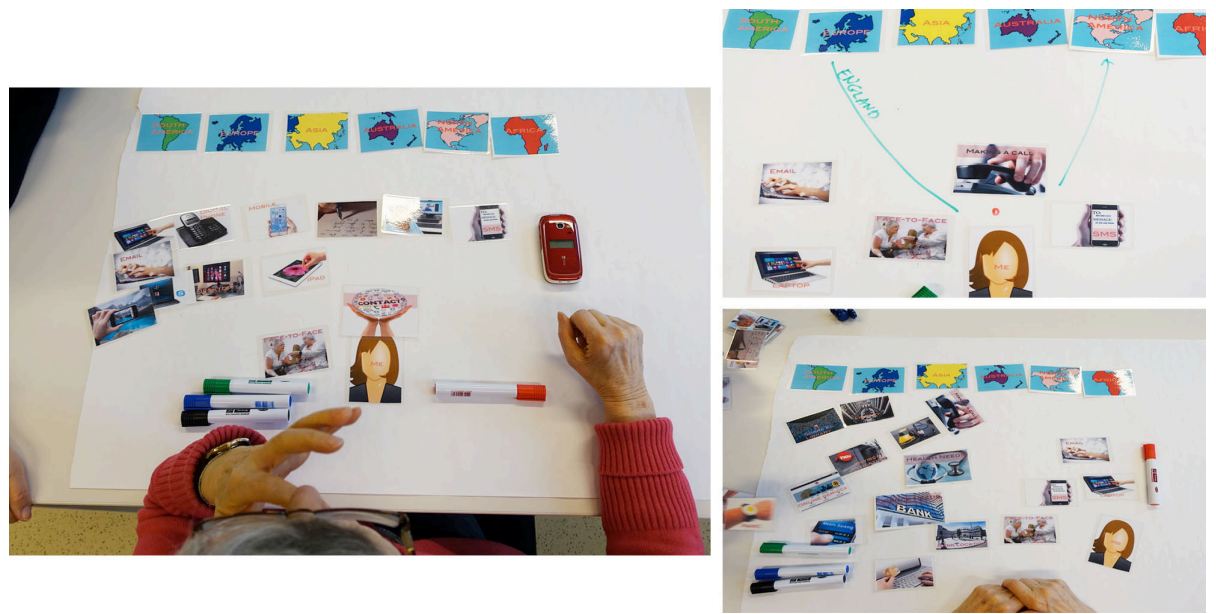

Fig. 2. An interviewee working with cards while talking about the role of ICT and her social connections.

\section{Vignettes.}

Vignettes were used to provide a context, a very short scenario for participants to reflect over when contemplating the future technologies. Depending on the interviewee's responses, one or more vignettes were introduced. If the interviewee did not wish to reflect over the future technologies, vignettes were skipped. Two sample scenarios are provided bellow. An image representing the first scenario was included with both maps and cards.

Vignette 1. Kaya is 83 and lives alone. In order to stay in touch, the family convinced her to get a tiny implant for the arm. When touched, the implant projects small hologram bubbles, with an image of a family member in each. Touching the bubble establishes a call to the person whose image it had.

Vignette 2. Ole is 93. He lives alone and spends much time watching TV. Alongside his $T V$, there is a large basket and on the sofa table there are two soft balls. One has the image of his son, and the other his brother. Choosing the one with the image of his son, Ole throws the ball into the basket. This establishes Skype connection and the TV now shows the Skype interface with an active call to his son. The son does not answer, the Skype shuts down and the TV re-starts. 


\subsection{Choosing Participants}

In contrast to many studies focusing on vulnerable groups of elderly [25], such as demented [23, 28], bereaved [29], or those with physical disabilities [30], this study focuses on active elderly without major health challenges at the time of the interview. As stated in the introduction, the study aimed at taking a perspective of active, welleducated elderly with successful careers behind them, who live alone. The criteria for inclusion in the study were: age (over 65), living alone in an urban setting, completed higher education, had a successful career, and had a positive relation with an adult child at the time of the recruitment. According to [31, 32], six to eight participants from homogeneous groups can give enough data for a rich description. Being at ease with the interviewer was important. Participants were, thus, recruited among acquaintances, friends and family, giving surprisingly many possible candidates. Six participants were chosen who satisfied the above recruitment criteria. In addition, they were chosen because they are usually candid, and thus, it could be expected that they would give unbiased opinions, in fact, that they would do their best to do so. Four participants worked previously in professions where high ethical awareness was expected. The age distribution for women was 71,73 and 76. Men were aged 67, 74 and 83. Career wise, two participants have practiced medicine (W73 and M74), one psychology (W71), one was an academic (M67), and two worked in business (W76 and M83). Five participants were retired, while one, (M67), was still partly employed. One man (M74) and one woman (W71) were ethnically Norwegian. Including participants who are not ethnically Norwegian, was seen as interesting in terms of social loneliness and connectedness. Four of the interviews were conducted in English and two in Norwegian; the author translated the latter.

\subsection{Interview plan}

The interviews were conducted on one-to-one bases, with two exceptions. In one case, the interviewee brought along a friend, who remained unengaged during the interview. In the second case, another researcher was present. On that occasion, the use of communication cards was tested. All interviews were conducted in quiet locations within the university (four interviews), or home (2 interviews), always with ample space for maps and cards. The shortest interview took about an hour, while the average length was about an hour and a half.

The following interview plan was implemented:

1. Can you tell a bit about technology that you use to communicate with others?

2. Please take a look at maps in front of you. Let us start with communication with friends and family map (or cards). Can you draw your communication network on that map? And then, add icons representing the kind of devices that you use for each?

3. How do you experience this map?

4. Repeat questions 2. and 3. for the contacts and services map and the future technology map (or cards).

5. Use a vignette. What are your reflections around this vignette?

6. Any other reflections on social connectedness? 


\section{$4 \quad$ Analysis and Discussion}

The interviews were coded and analyzed based on categories related to interactionist theory, i.e. perception of quality and quantity of social connectedness. It was evident from interviews that access to services was important for connectedness and the personal safety. Only basic services such as banking, health services, and social services were explicitly mentioned, leaving it up to participants to add any additional services that could be important for them. Some have added travel related services, while others were concerned with alarms that could notify someone in the case of a medical emergency. Finally, the future needs were explored, in the same categories.

\subsection{General use of ICT}

Although many studies exist on the general use of ICT among elderly, e.g., [11, 33], the use among interviewees is described briefly.

All participants had a phone and used it regularly. Four of the participants had smartphones. One of them got a brand new iPhone 6 plus as soon as it became available (M74). Two participants had ordinary phones (W71, M83). All were able to make a call, receive an SMS, and all but one could also send an SMS. "See, this is my mobile [note: shown in Fig. 2]. It is not some kind of a smart mobile; it is a completely idiotic one. I can call, and I can get SMSs, but I cannot answer. I never bothered to learn." (W71)

Further, all interviewees were able to take pictures and send or receive them. Three persons with smartphones used a much broader set of features and apps, such as dictation, voice over Internet, advanced photo editing, Dropbox and so on. One of the participants, upon seeing HD Recording app used during the interview, said: "It is an app, right? How do I get it? "(M67)

All participants either owned a PC (M74, M67), a laptop (M83, W71, M67) or a tablet (W73, W76, M67). They used these to varying degrees. One woman barely used her laptop, another used her tablet daily while the third used it only occasionally. The men used their devices for work or hobby daily, two of them extensively so. The participants showed no signs of dislike or fear of new technology, although some (W71 and W76) expressed a wish to preserve a lifestyle with as little technology in it as possible.

\subsection{The quality of connectedness}

Personal.

Phone calls seemed to be an acceptable way to connect to friends and family.

"I call my family and friends in the States all the time. It is the best I can do from here [note: Norway], and it is OK”. (M67)

"I have four people that I speak to more or less daily. Every day. It is comforting, and when somebody skips a call, I miss it”. (W76)

However, the interviewee also remarks that while phones enable staying in touch, aging does reduce desire for face-to-face connections, as they require effort. 
"I have 2 sisters living far away. I talk to them almost every Sunday. I wished to see them in person much more when I was younger, but now, I think that the phone is what I have the energy for, even if we lived in the same city. It is all right to just check in with them". (W76)

While recognizing that technology helps stay in touch, another participant raises a concern that it makes it easier to miss the opportunity for face-to-face contact.

"The communication, what is it? I think that talking to my child is a real connection. So when I want that connection, I pick up the phone. I find the reason to call. So we communicate, using technology. It does not replace the real ting. It helps to keep it going. One can get addicted to technology and try to replace the real care with it. It does not work". (W73)

Sometimes, the quality of face-to-face contact is interrupted by technology.

"When I am with my son, he often plays with his phone. Sometimes there is too little human contact." (W71)

One participant expressed that technology may serve the purpose of making the connection, extending it, even when the physical body is no longer there.

"I have a laptop. I am not really good at using it. But I started this project of organizing my pictures. It is fun. I have this young man who comes twice a week for 4 hours, so we organize pictures and write a bit of text together. Perhaps, it all turns into a book, or something for my family when I am no longer here. This is also communication. Using technology to stay in touch, in a way, even when I am gone”. (M83)

"It is the quality of friendships, it is the sense of community that counts". (M74)

This last sentence summarizes prevailing sentiments about the technology. While it may be fun, especially when used in active and constructive, even creative manner, it was not experienced as a tool that helps the quality of a contact. Rather, it was helping to 'stay in touch' and to prevent loss of existing connections.

Services.

Looking into services, for two of the female participants (W73 and W76), safety was important. One had an alarm installed in her flat, while the other remarked:

"I also want to have a fast and reliable communication with someone [note: in case of an emergency]. If one gets a stroke, the response needs to be really fast”. (W73).

The remaining participants did not talk about alarms or medical emergencies. A participant, who travels a lot, expressed a need for personalized travel services, perhaps also better food services.

A female participant tells a story:

"I wanted to extend my passport and I was trying to find the phone number to the police. There are no phone books any longer. I had to call my son to ask for the number. So, I called to make an appointment. The person who answered the call said that I have to book online. ... I was so angry. I went totally into an impotent rage. They must know that there still are people on the higher end of age that travel and are not Internet oriented. I see that I am becoming a museum object. I am a Stone Age woman, a Venus of Willendorf". W(71)

With only one exception, participants expressed a desire for all fashioned services to remain, sometimes in addition to electronic ones. One of the participants said: 
"I like to find out what kinds of services am I entitled to get. When I do, I always inform my friends and family what they too can get. I do not learn this from the Internet, but from human contacts. It is funny, I teach my friends how to fill forms so that they too can deny electronic services and have everything sent via surface mail. I do not know for how long I can stay out of it, but I am fighting this online thing." (W76)

The old fashioned services were part of the perception of being well connected:

"I like to go to the bank, or walk to my doctors office. I like to know people working there and I do not like to talk over the phone to people, or worse, machines, that I do not know." (M83)

This kind of personal connection to services, and people providing them, mattered. This way of connectedness was experienced as being in danger of disappearing, and the technology was to blame for it.

Future technologies.

Discussions on the future technology were mostly not very spirited.

"It is too late for me to consider the future technology. No point in thinking about it." (M83)

"No! Absolutely not. We are not talking about future technology. I am a cave dweller." (W71)

"I do not really want to think about any future technology." (W76)

"Holographic computing probably would not be interesting to me partly because I have a choice of voice or voice and video already. I often use voice only. This allows me to concentrate and really reach out to the person I am taking to, with voice. Using video, it tends to be the case that communication is a bit more superficial." (M67)

One woman had a different view. If the technology could help her overcome one of her personal barriers, the language, she would take a chance with technology:

"Those who moved out of their own country to Norway many, many years ago, are now getting old. So, as old people, perhaps they live alone, but they also really need to communicate. That chip should be used so that they do not feel isolated. If one does not have the language, and can not express themselves clearly, then one is isolated. Isolation is an open prison for me. I would get that chip implanted in my brain, if I could speak different languages well at once." (W73)

\subsection{The quantity of connections}

The interactionist theory assumption that people would be interested in evaluating their connections also by quantity was evident, whether they had a large number of connections or a single one.

"I talk mostly to my son" (W71).

"I have acquaintances in Norway, probably 50, vs. about 20 in the US. But all of my close friends and family are in the US" (M67), [see Fig. 1, top row of maps, where the participant used the letter A for acquaintances, $\mathrm{F}$ for family and $\mathrm{C}$ for close friends, adding the number of such connections in parenthesis].

"I have a lot of connections, most numerous are acquaintances and my old clients, I really know a lot of people. They are a network, although perhaps not of a kind to keep in close contact with. I cannot put them all here. But I would say that I have four primary close connections that I care most about." (M74) 
The three male participants all expressed that the number of connections was important to consider, and were considering options to increase the number of meaningful connections by building a community, or moving into one. The three female participants were happy to have at least one strong close connection, and the number of connections was less important. This indicates that some gender differences may exist regarding the importance of emotional connectedness and the need for broader networks.

\subsection{Tools evaluation}

Drawing their personal connections to the friends and family map was really interesting for all participants. Three participants kept taking pictures, as depicted in Fig. 1, while making their maps. One remarked: "I have never thought about it this way" (W73). In one case, seeing explicitly the map of the connections, brought about an insight that had a consequence for participant's life choice: "I see that I am being at risk of isolation in Norway. That would be a major factor in wanting to, not just wanting, but actively building another life style and life in the US." (M67)

Thus, the maps have worked well for inquiry into social connectedness, also to necessary services. The cards did not work as well as the maps. They seemed to obstruct drawing in connections and other things on the paper. Also, the act of drawing connections to the map seemed to lead to a deeper reflection over connections, than a more active approach involving browsing and placing the cards on a large sheet of paper did. Furthermore, the effect of a sense of a new perspective on their connections that the participants had with maps was not the same for the card user.

Vignettes had limited usefulness, as most of the participants were really not interested in discussing the future technology. Perhaps, the video approach as described in [34] could engage the participants better. Only two participants engaged:

"Actually, this implant on the hand is good, something like that would always be part of me. In all kinds of emergencies." (W73)

"I would like to have a ball to open the Skype on my TV. Only, I do not know who would pick up the ball all the time. My dog, perhaps. I like the playfulness of it, but would not really want anything like that." (M74)

Overall, the interview tool that best supported reflections, was the friends and family communication map.

\section{Conclusion}

The relative disinterest in technology that the participants showed through described interviews did not originate from any difficulty in understanding how today's, or future, technologies could support them. Rather, when it came to relations and services, most of them had preference for real, face-to-face contacts. Even if it required, as for one of the participants, the move to another continent, as the close relations were preferred to more numerous casual ones in Norway. The phones were an acceptable solution for keeping in touch, but the participants were aware that this was not the same as a real contact. Even casual contacts, such as those with service providers in banks, were more valued in person than online, and these service providers were ex- 
perienced as parts of the individual's network, parts of their of social connectedness. In conclusion, the findings from interviews indicate that, even though they live alone, participants do not view the technology as a possible solution to social loneliness. This perception, of course, could change as their circumstances change. Several findings indicated some differences between male and female participants and those would warrant further exploration, e.g., relation between gender and the sense of social connectedness. This study is too small to have external validity, but clearly indicates that even when elderly could use the ICT for fulfillment of their social networking needs, they choose, or prefer, non-technological solutions, even when those may lead to increased loneliness.

\section{References}

1. Christensen, D.A.: Active ageing: country report Norway. (2003).

2. Syse, A., Pham, D.Q.: Befolkningsframskrivinger 2014-2100: Dødelighet og levealder SSB, http://www.ssb.no/befolkning/artikler-og-publikasjoner/befolkningsframskrivinger2014-2100-dodelighet-og-levealder.

3. Keilman, N., Christiansen, S.: Norwegian Elderly Less Likely to Live Alone in the Future. Eur J Population. 26, 47-72 (2009).

4. Sundsli, K., Söderhamn, U., Espnes, G.A., Söderhamn, O.: Ability for self-care in urban living older people in southern Norway. J Multidiscip Healthc. 5, 85-95 (2012).

5. The National Council for Senior Citizens' action plan - Nyheter - Seniorporten, http://www.seniorporten.no/Nyheter/The+National+Council+for+Senior+Citizens $\% 27+a c$ tion+plan.312320.cms.

6. Russell, D.W., Cutrona, C.E., de la Mora, A., Wallace, R.B.: Loneliness and nursing home admission among rural older adults. Psychology and Aging. 12, 574-589 (1997).

7. Perissinotto, C.M., Stijacic Cenzer, I., Covinsky, K.E.: Loneliness in older persons: a predictor of functional decline and death. Arch. Intern. Med. 172, 1078-1083 (2012).

8. Fokkema, T., De Jong Gierveld, J., Dykstra, P.A.: Cross-National Differences in Older Adult Loneliness. The Journal of Psychology. 146, 201-228 (2012).

9. Cattan, M., White, M., Bond, J., Learmouth, A.: Preventing social isolation and loneliness among older people: a systematic review of health promotion interventions. Ageing \& Society. 25, 41-67 (2005).

10. Blythe, M.A., Monk, A.F., Doughty, K.: Socially dependable design: The challenge of ageing populations for HCI. Interact. Comput. 17, 672-689 (2005).

11. Heart, T., Kalderon, E.: Older adults: Are they ready to adopt health-related ICT? International Journal of Medical Informatics. 82, e209-e231 (2013).

12. Wiklund Axelsson, S., Melander Wikman, A., Näslund, A., Nyberg, L.: Older people's health-related ICT-use in Sweden. Gerontechnology. 12, (2013).

13. Culén, A.L., Bratteteig, T.: Touch-Screens and Elderly users: A Perfect Match? ACHI 2013, The Sixth International Conference on Advances in Computer-Human Interactions. pp. 460-465 (2013).

14. Culén, A.L., Finken, S., Bratteteig, T.: Design and Interaction in a Smart Gym: Cognitive and Bodily Mastering. In: Holzinger, A., Ziefle, M., Hitz, M., and Debevc, M. (eds.) Human Factors in Computing and Informatics. pp. 609-616. Springer Berlin Heidelberg (2013).

15. Bruk av IKT i husholdningene - SSB, http://www.ssb.no/ikthus.

16. Mancini, J.A., Blieszner, R.: Aging Parents and Adult Children: Research Themes in Intergenerational Relations. Journal of Marriage and Family. 51, 275-290 (1989). 
17. Hawkley, L.C., Cacioppo, J.T.: Loneliness matters: a theoretical and empirical review of consequences and mechanisms. Ann Behav Med. 40,218-227 (2010).

18. Victor, C., Scambler, S., Bond, J., Bowling, A.: Being alone in later life: loneliness, social

Weiss, R.S.: Loneliness: The Experience of Emotional and Social Isolation. MIT Press, Cambridge, Mass (1974) 19.

isolation and living alone. Reviews in Clinical Gerontology. 10, 407-417 (2000).

20. Neergaard, M.A., Olesen, F., Andersen, R.S., Sondergaard, J.: Qualitative description - the poor cousin of health research? BMC Med Res Methodol. 9, 52 (2009).

21. Dourish, P.: Responsibilities and Implications: Further Thoughts on Ethnography and Design. Proceedings of the 2007 Conference on Designing for User eXperiences. pp. 25:225:16. ACM, New York, NY, USA (2007).

22. Lindsay, S., Brittain, K., Jackson, D., Ladha, C., Ladha, K., Olivier, P.: Empathy, participatory design and people with dementia. Proceedings of the 2012 ACM annual conference on Human Factors in Computing Systems. pp. 521-530. ACM, New York, NY, USA (2012).

23. Sixsmith, A.J., Gibson, G., Orpwood, R.D., Torrington, J.M.: Developing a technology "wish-list"to enhance the quality of life of people with dementia. Gerontechnology. 6, 219 (2007).

24. Living Profiles » Map your social tree, http://livingprofiles.net/?page_id=99.

25. Culén, A.L., Velden, M. van der: The Digital Life of Vulnerable Users: Designing with Children, Patients, and Elderly. In: Aanestad, M. and Bratteteig, T. (eds.) Nordic Contributions in IS Research. pp. 53-71. Springer Berlin Heidelberg (2013).

26. Culén, A.L., van der Velden, M., Herstad, J.: Travel Experience Cards: Capturing User Experiences in Public Transportation. The Seventh International Conference on Advances in Computer-Human Interactions. ThinkMind (2014).

27. Karabeg, A., Akkøk, N.: Visual Representations and the Web. In: Griffin, R., Chandler, S., and Cowden, Belle Doyle (eds.) Visual Literacy And Development: An African Experience. pp. 115-123. The International Visual Literacy Association (2005).

28. Malinowsky, C., Almkvist, O., Kottorp, A., Nygård, L.: Ability to manage everyday technology: a comparison of persons with dementia or mild cognitive impairment and older adults without cognitive impairment. Disabil Rehabil Assist Technol. 5, 462-469 (2010).

29. Massimi, M., Baecker, R.M.: A Death in the Family: Opportunities for Designing Technologies for the Bereaved. Proceedings of the SIGCHI Conference on Human Factors in Computing Systems. pp. 1821-1830. ACM, New York, NY, USA (2010).

30. Stefanov, D.H., Bien, Z., Bang, W.-C.: The smart house for older persons and persons with physical disabilities: structure, technology arrangements, and perspectives. IEEE Transactions on Neural Systems and Rehabilitation Engineering. 12, 228-250 (2004).

31. Holloway, I., Wheeler, S.: Qualitative Research in Nursing and Healthcare. WileyBlackwell, Chichester, West Sussex, U.K. ; Ames, Iowa (2009).

32. Van der Velden, M., El Emam, K.: "Not all my friends need to know": a qualitative study of teenage patients, privacy, and social media. J Am Med Inform Assoc. 20, 16-24 (2013).

33. Selwyn, N., Gorard, S., Furlong, J., Madden, L.: Older adults' use of information and communications technology in everyday life. Ageing \& Society. 23, 561-582 (2003).

34. Lindsay, S., Jackson, D., Schofield, G., Olivier, P.: Engaging older people using participatory design. Proceedings of the 2012 ACM annual conference on Human Factors in Computing Systems. pp. 1199-1208. ACM, New York, NY, USA (2012). 